\title{
Differential Histone-DNA Interactions Dictate Nucleosome Recognition of the Pioneer Transcription Factor Sox
}

\author{
Burcu Ozden ${ }^{1,2+}$, Ramachandran Boopathi ${ }^{3,4,5+}$, Ayşe Berçin Barlas ${ }^{1,2}$, Imtiaz N. Lone $^{2}$, Jan Bednar ${ }^{3}$, \\ Carlo Petosa ${ }^{4}$, Seyit Kale ${ }^{1}$, Ali Hamiche ${ }^{6 *}$, Dimitar Angelov ${ }^{5 *}$, Stefan Dimitrov ${ }^{1,3 *}$, Ezgi Karaca ${ }^{1,2 *}$ \\ ${ }^{1}$ Izmir Biomedicine and Genome Center, Dokuz Eylul University Health Campus, Izmir 35330, Turkey \\ ${ }^{2}$ Izmir International Biomedicine and Genome Institute, Dokuz Eylül University, Izmir, 35340, Turkey \\ ${ }^{3}$ Université Grenoble Alpes, CNRS UMR 5309, INSERM U1209, Institute for Advanced Biosciences \\ (IAB), Site Sante' - Allée des Alpes, La Tronche, 38700, France \\ ${ }^{4}$ Université Grenoble Alpes, CNRS, CEA, Institut de Biologie Structurale (IBS), Grenoble, 38000 , \\ France \\ 5Université de Lyon, Ecole Normale Supérieure de Lyon, CNRS, Laboratoire de Biologie et de Mode' \\ lisation de la Cellule LBMC, 46 Allée d'Italie, Lyon, 69007, France \\ ${ }^{6}$ Département de Génomique Fonctionnelle et Cancer, Institut de Génétique et Biologie Moléculaire et \\ Cellulaire (IGBMC)/Université de Strasbourg/CNRS/INSERM, Illkirch Cedex, 67404, France.
}

\author{
+Joint First Authors \\ *Corresponding authors: Ezgi Karaca, Stefan Dimitrov, Ali Hamiche, Dimitar Angelov \\ Correspondence: ezgi.karaca@ibg.edu.tr
}

\section{ABSTRACT}

Pioneer transcription factors (PTFs) have the remarkable ability to directly bind to chromatin for stimulating vital cellular processes. Expanding on the recent findings, we aim to unravel the universal binding mode of the famous Sox PTF. Our findings show that the base specific hydrogen bonding (base reading) and the local DNA changes (shape reading) are required for sequence-specific nucleosomal DNA recognition by Sox. Among different nucleosomal positions, base and shape reading can be satisfied at super helical location 2 (SHL2). This indicates that due to distinct histoneDNA interactions, SHL2 acts transparently to Sox binding, where SHL4 permits solely shape reading, and SHLO (dyad) allows no reading. We also show that at SHL2, Sox binds to its recognition sequence without imposing any major conformational changes, if its consensus DNA sequence is located at the solvent-facing nucleosomal DNA strand. These data explain how Sox have evolved to perfectly adapt for chromatin binding. 


\section{INTRODUCTION}

The nucleosome core particles (NCPs) are the basic chromatin repeating units, packaging the eukaryotic genome (1). The NCPs, connected with the linker DNA, make up the $10 \mathrm{~nm}$ chromatin filament, which, upon binding of the linker histone $\mathrm{H} 1$, folds into higher order chromatin structures (25). The NCP is composed of a core histone octamer (two of H2A, H2B, H3 and H4 proteins) and 147 base pairs (bp) of DNA. The NCP wraps around the histone octamer in 1.67 left-handed helical turns (6). DNA positioning on the NCP is described as superhelical locations (SHLs), where each SHL is separated by $\sim 10$ bp nucleotides and their major grooves face towards the histones ( $\mathrm{SHL} \pm 7$ to \pm 1 ) (7) (Figure 1B). The SHLs are numbered according to central DNA sequence, which is their coordinate origin, i.e., the nucleosomal dyad (SHLO). At each SHL, the distinct histone-DNA interactions impact accessibility of DNA to proteins, such as chromatin remodelers (8). The chromatin remodelers aid transcription factors (TFs) to reach to their recognition sequences on the nucleosomal DNA by altering the nucleosomal DNA conformation $(9,10)$. In the absence of remodelers, nucleosomes present an impediment to transcription, as the vast majority of TFs are unable to overcome the nucleosomal barrier to recognize their cognate sequence (11-17). An exception to this rule is the pioneer transcription factors (PTFs). Unlike conventional TFs, PTFs directly bind to nucleosomally organized DNA and assist the assembly of complex transcriptional machineries (1820). This fact delegates PTFs a central role in establishing competence for gene expression, in initiating cellular programming and reprogramming, as well as in other essential chromatin-templated processes (21).

In the last decade, multiple studies have poised to explore the interaction landscape between PTFs and the NCP (18-20). PTFs are commonly proposed to have HMG, Fork-head, POU, ZF, and bHLH domains $(20,22)$. Among these, the HMG domain is composed of 79 amino acids, folding into a simple three-helix architecture arranged in a boomerang L-shape (23-26) (Figure 1A). Like the other PTFs, HMG domains have been demonstrated to guide a diverse range of vital processes (2734). As an example, the HMG domain carrying Sox2 was shown to be a part of the TF cocktail, capable of inducing pluripotent stem cells from somatic human cells $(35,36)$. Another HMG protein, Sox4, is a crucial factor in the epithelial to mesenchymal transition, a fundamental process operating in cancer progression and metastasis $(37,38)$. Together with other eighteen proteins, Sox2/4 make up the Sox family, the so-called "ultimate utility player of the cell" $(36,39)$. Within this family, each Sox encompasses the highly conserved HMG domain, Sox-HMG, recognizing the cognate "TTGT" at the DNA minor groove. For the sake of simplicity, from this point and on, we will refer to Sox-HMG as Sox. Sox proteins bind to DNA minor groove by establishing base specific hydrogen bonds (base reading), as well as, by imposing extreme DNA distortion regulated via hydrophobic Sox:DNA interactions (shape reading) (39-42) (Figure 1A). Both base and shape reading interactions are invariant among all Sox:DNA complexes (40). 
In 2020, Dodonova et al. unveiled the nucleosomal recognition mode of Sox2 and Sox11. In their complex, Sox cognate sequence was inserted into the nucleosomal DNA at superhelical location +2 (SHL2), where its TTGT faces the histone octamer (43) (Figure 1B). At SHL2, Sox2:NCP and Sox11:NCP complexes came out structurally identical. In both complexes, the binding of Sox is accompanied by a strong local distortion of the nucleosomal DNA, involving a $7 \AA$ widening of the minor groove. The tight interactions between Sox and nucleosomal DNA resulted in the pulling of the DNA away from the histone octamer by $\sim 4 \AA$. These DNA perturbations are reminiscent to the ones induced by the binding of Sox to free DNA, suggesting that Sox:DNA interactions are conserved at SHL2 (44-49). As an intriguing observation, in both structures, 25 bp from the end of the nucleosomal DNA (at SHL-7, SHL-6 and SHL-5) are found to be detached from the histone octamer due to steric clashes formed between Sox and the adjacent gyre (Supplementary Figure 1A-B). At higher Sox concentrations, a second protein molecule was able to specifically bind to NCP, but this time at SHL2. This binding resulted in the detachment of an additional 25 DNA bp from the histone octamer, from the other nucleosomal DNA end (at SHL+7, SHL+6 and $S H L+5$ ). The binding of the Sox-factor appears to reposition the $\mathrm{H} 4$ histone tail as well. In this way, Sox could alter the canonical nucleosome-nucleosome contacts and open the chromatin fiber locally (43).

Expanding on these observations, we aim to unravel the universal PTF binding rules of Sox, i.e., (i) how Sox binding occurs at SHL2, if its cognate sequence is located on the solvent facing strand (the complementary strand to the one used by Dodonova et. al.), (ii) whether Sox can be accommodated by other SHLs, such as SHL4 and dyad. To explore these points, we use an integrative approach, where we combine in silico (integrative modeling and molecular dynamics simulations) and experimental $(\cdot \mathrm{OH}$ and UV laser footprinting) approaches. Our data show that Sox can bind to SHL2 without imposing any major DNA rearrangements when its cognate sequence faces the solvent. We also demonstrate that at SHL2, special histone:DNA interactions dictate the base specific Sox recognition, which is not realized at other SHL positions. 


\section{MATERIAL AND METHODS}

Molecular Dynamic Simulations and Modeling of the Sox:Nucleosome Complex: To explore the NCP invasion by Sox, we performed a series of integrative modeling and simulation cycles, making up our Dynamic Integrative Modeling (DIM) approach. Our DIM protocol is composed of three steps (Supplementary Figure 2):

(1) Modeling cognate sequence inserted 601 Widom DNA sequence ( $\mathrm{pdb}$ id:3lz0, (50)) and the Molecular Dynamics (MD) simulations of this model (free nucleosome).

(2) From these simulations, we took the Sox-binding-compatible free nucleosome conformers to model the initial Sox11 bound nucleosome complexes at three super helical locations (SHLS), i.e., SHLO (dyad), SHL2 and SHL4.

(3) The MD simulations of the constructed Sox11 bound nucleosome complexes.

Next to the listed MD simulations, we also simulated Sox11:DNA complex (pdb id:6t78, (43)) to serve as a reference state.

All of the MD simulations were performed by using the GROMACS simulation package (Gromacs 2019 and Gromacs 5.1.4) (51) under the effect of Amber Parmbsc1 force field (52). The water model was TIP3P. The $\mathrm{NaCl}$ concentration of the whole system was kept at $0.15 \mathrm{M}$. The simulation box was a dodecahedron one, while having a minimum distance of $12 \AA$ between the biological molecule and the edges of the simulation box. The temperature was kept at $310 \mathrm{~K}$ throughout the simulation.

At the end of the simulations, minor groove widening and P-RMSD (Root Mean Square Deviations of the DNA Phosphorus atoms) metrics were computed. Minor groove widths were calculated with 3DNA (53). Sox2:NCP complex (pdb id:6t7b, (43)) was used as a reference state for minor groove opening. P-RMSD measures the mean squared distance over the phosphorus atoms of seven nucleotides' (5'-GACAATG-3') between the reference state and the model. We used Sox11:DNA complex (pdb id: 6t78, (43)) as a reference and performed fitting with Profit (Martin, A.C.R., http://www.bioinf.org.uk/software/profit/). The reference seven nucleotides correspond to (-3rd)-3rd, 17th-23rd, 38th-44th nucleotide ranges at dyad, SHL2 and SHL4 regions, respectively. The interaction profiles of the complexes were computed with the Interfacea Python library (https://github.com/JoaoRodrigues/interfacea).

(1) The MD simulations of the 601 Widom DNA sequence: We inserted a special sequence, bearing the Sox consensus sequence 5 -GGACAATGGAGG-3' at dyad, SHL2 and SHL4 by using 3DNA (53). The mutated sequence corresponds to $\left(-4^{\text {th }}\right)-7^{\text {th }}, 16^{\text {th }}-27^{\text {th }}$ and $37^{\text {th }}-48^{\text {th }}$ nucleotides in the forward DNA chain, leading to the following sequence: 5'- 
The mutant nucleosome is named as $601-\mathrm{SHL} 024$, which was subjected to MD simulations, totaling 2 $\mu$ s long $(2 \times 1 \mu s)$. The conformations with the lowest P-RMSD values were selected to model the Sox11 bound nucleosome complexes.

(2-3) The modeling and simulation of the Sox11:NCP complexes: The free nucleosome conformers, reflecting the lowest P-RMSD at the dyad, at the SHL2 and at the SHL4 were isolated. The initial crude models were refined in HADDOCK, while imposing the Sox binding mode as restraints (54). Here, we imposed the crystal Sox11:DNA distances, measured between $56^{\text {th }}, 57^{\text {th }}(\mathrm{FM})$ residues of Sox 11 and $0^{\text {th }}, 20^{\text {th }}$, and $41^{\text {st }}$ nucleotides (forward strand), respectively. This restraint ensures the reproduction of the hydrophobic wedge interactions. The HADDOCK models were subjected to two parallel MD simulations, totaling $1 \mu \mathrm{s}$. At the end, the conformations with the lowest P-RMSD were isolated and kept as final Sox11 bound nucleosome (Sox:dyad, Sox:SHL2 and Sox:SHL4) models.

The MD Simulation of the Sox11:DNA complex: Here, Sox11:DNA complex(pdb id: 6t78) was subjected to two parallel MD simulations, totaling $1 \mu \mathrm{s}$.

Sox6 HMG domain cloning and purification: HMG domain of human Sox6 (618 - 697 aminoacids) gene was cloned in $\mathrm{pET} 28 \mathrm{~b}$ vector in between $\mathrm{Ndel}$ and Xhol restriction sites. The $\mathrm{N}$ terminal Histagged Sox6 HMG domain was produced in Escherichia coli BL21(DE3) pLYsS cells. Briefly $200 \mathrm{ng}$ of plasmid was used to transform into $E$. coli cells, after transformation bacteria were platted on LB agar plates supplemented with kanamycin \& chloramphenicol, and incubated overnight at $37^{\circ} \mathrm{C}$. Single colonies were added to $3 \mathrm{ml}$ of LB medium (kanamycin+ chloramphenicol) for 12 to 16 hours at $37^{\circ} \mathrm{C}$ under shaking at $200 \mathrm{rpm}$ speed. $1 \mathrm{ml}$ of amplified bacteria was added to $300 \mathrm{ml}$ LB (kanamycin+ chloramphenicol) and left overnight at $37^{\circ} \mathrm{C}$ and $200 \mathrm{rpm}$. For each liter of LB (kanamycin+ chloramphenicol) needed, $10 \mathrm{ml}$ of transformed bacteria were added. After 3 hours of incubation, OD at $600 \mathrm{~nm}$ was measured. If the OD600 was comprised between 0.5 and 0.6 , bacteria were induced with $0.2 \mathrm{mM} \mathrm{IPTG}$ (isopropyl-beta-D-thiogalactopyranoside) at $37^{\circ} \mathrm{C}$ for $3-4$ hours at $200 \mathrm{rpm}$. After induction bacteria were pelleted at $5000 \mathrm{~g}$ for $20 \mathrm{~min}$ at $4^{\circ} \mathrm{C}$. The recombinant human Sox $6 \mathrm{HMG}$ domain was purified from supernatant of bacterial lysate by using NiNTA resin (Complete His-Tag purification Resin, Roche) and followed by SP sepharose column chromatography (GE Healthcare). Purity of purified HMG doman of Sox6 protein was analyzed by using $18 \%$ SDS-PAGE and stained with coommassie blue.

Core histone purification: Human histones $\mathrm{H} 2 \mathrm{~A}, \mathrm{H} 2 \mathrm{~B}$ and $\mathrm{H} 3$ were sub-cloned in pHCE vector system and human histone $\mathrm{H} 4$ sub-cloned in $\mathrm{pET} 15 \mathrm{~b}$ vector system. Histones $\mathrm{H} 2 \mathrm{~A}, \mathrm{H} 2 \mathrm{~B}$ and $\mathrm{H} 3$ were produced in Escherichia coli BL21(DE3) cells and human H4 was produced in E. coli JM109(DE3) cells. Core histones were produced as $\mathrm{N}$-terminal His-tagged proteins in $\mathrm{E}$. coli cells in the absence of T7 RNA polymerase by omitting the addition of isopropyl-P-D-thiogalactopyranoside, which induces the T7 RNA polymerase production in BL21(DE3) and JM109(DE3) cells. Briefly $200 \mathrm{ng}$ of plasmid (for each histone) were used to transform into respective E. coli strains. 10 colonies were inoculated into $2 \mathrm{~L} \mathrm{LB}$ broth (ampicillin final concentration $50 \mu \mathrm{g} / \mathrm{ml}$ ) in $5 \mathrm{~L}$ flask and left overnight at $37^{\circ} \mathrm{C}$ and 200 rpm. Each liter of bacteria was pelleted at $5000 \mathrm{~g}$ for $20 \mathrm{~min}$ at $4^{\circ} \mathrm{C}$. The cells producing recombinant 
histones were collected and disrupted by sonication in $50 \mathrm{ml}$ of buffer A (50 mM Tris-HC1 (pH 8.0), $500 \mathrm{mM} \mathrm{NaC1}, 1 \mathrm{mM} \mathrm{PMSF}$, and $5 \%$ glycerol). After centrifugation $\left(27,216 \times \mathrm{g} ; 20 \mathrm{~min} ; 4^{\circ} \mathrm{C}\right)$, the pellet containing His-tagged histones as insoluble forms was resuspended in $50 \mathrm{ml}$ of buffer $\mathrm{A}$ containing $7 \mathrm{M}$ guanidine hydrochloride. After centrifugation $\left(27,216 \mathrm{x} \mathrm{g} ; 20 \mathrm{~min} ; 4^{\circ} \mathrm{C}\right)$, the supernatants containing the His-tagged histones were combined with NiNTA resin (Complete His-Tag purification Resin, Roche) ( $1 \mathrm{~mL}$ of Ni-NTA per $1 \mathrm{~L}$ of bacteria) and were mixed by rotation for $1 \mathrm{hr}$ at $4{ }^{\circ} \mathrm{C}$. The agarose beads were packed into an Econo-column (Bio-Rad) and were then washed with $100 \mathrm{ml}$ of buffer B (50 mM Tris-HC1 (pH 8.0), $500 \mathrm{mM} \mathrm{NaC1,} 6 \mathrm{M}$ urea, $5 \mathrm{mM}$ imidazole, and $5 \%$ glycerol). The His-tagged histones were eluted by a $100 \mathrm{ml}$ linear gradient of imidazole from 5 to 500 $\mathrm{mM}$ in buffer $\mathrm{B}$, and the samples were dialyzed against buffer $\mathrm{C}(5 \mathrm{mM}$ Tris-HC1 $(\mathrm{pH} 7.5)$ and $2 \mathrm{mM}$ 2-mercaptoethanol).

The $\mathrm{N}$-terminal $6 \mathrm{x}$ His tags were removed from the histones by thrombin protease (GE Healthcare) treatments using 1 unit per $1 \mathrm{mg}$ of protein for $3-5 \mathrm{~h}$ at $4^{\circ} \mathrm{C}$. The removal of the His tags was confirmed by SDS-16\% polyacrylamide gel electrophoresis (PAGE); the recombinant histones without the His tag migrated faster than the His-tagged histones. After uncoupling of the His tag, each histone was subjected to Resource $S$ column chromatography (GE Healthcare). The column was washed with buffer D (20 mM sodium acetate (pH 5.2), $200 \mathrm{mM} \mathrm{NaC1,} 5 \mathrm{mM}$ 2-mercaptoethanol, $1 \mathrm{mM}$ EDTA, and $6 \mathrm{M}$ urea), and each histone was eluted by a linear gradient of $\mathrm{NaC} 1$ from 200 to $900 \mathrm{mM}$ in buffer $\mathrm{D}$. The fractions containing the pure histone were mixed and stored in $-80^{\circ} \mathrm{C}$.

Histone tetramers and dimers preparation: To prepare tetramers and dimers human $\mathrm{H} 3$ \& $\mathrm{H} 4$ and human $\mathrm{H} 2 \mathrm{~A} \& \mathrm{H} 2 \mathrm{~B}$ were mixed in an equimolar ratio, and dialyzed overnight in HFB buffer (2M NaCl, $10 \mathrm{mM}$ Tris pH7.4, $1 \mathrm{mM}$ EDTA pH 8 and $10 \mathrm{mM} \beta$-mercaptoethanol). After dialysis the supernatant containing folded tetramers and dimers were subjected to Superose 6 prep grade XK 16/70 size exclusion column (GE Healthcare) purification using HFB buffer. The major fractions containing purified tetramers and dimers were mixed. For long time storage, tetramers and dimers were mixed with $\mathrm{NaCl}$ saturated glycerol to achieve the final glycerol concentration around $15-20 \%$ and stored at $20^{\circ} \mathrm{C}$.

Preparation of DNA fragments: The 255 bp of 601 DNA constructs containing Sox 6 consensus motif 5 -GGACAATGGAGG-3` positioned in different places were produced by chemical synthesis method and cloned into standard vector pEX-A by Eurofins Genomics, Germany. The position of Sox6 binding sites in the 601 constructs were mentioned below,

Sox-SHL0 (dyad): (Sox6 binding motif located at 66bp away from the end of nucleosomal DNA)

GCATGATTCTTAAGACCGAGTTCATCCCTTATGTGATGGACCCTATACGCGGCCGCCATCAGAAT CCCGGTGCCGAGGCCGCTCAATTGGTCGTAGACAGCTCTAGCACCGCTTAAACGCACGTAGGA CAATGGAGGCGCGTTTTAACCGCCAAGGGGATTACTCCCTAGTCTCCAGGCACGTGTCAGATAT ATACATCGATGTGCATGTATTGAACAGCGACCTTGCCGGTGCCAGTCGGATAGAATTCCGGAC

Sox6-SHL2: (Sox6 binding motif located at 46bp away from the end of nucleosomal DNA) 
GCATGATTCTTAAGACCGAGTTCATCCCTTATGTGATGGACCCTATACGCGGCCGCCATCAGAAT CCCGGTGCCGAGGCCGCTCAATTGGTCGTAGACAGCTCTAGCACCGCTTAAACGCACGTACGC GCTGTCCCCCGCGTTTTGGACAATGGAGGCATTACTCCCTAGTCTCCAGGCACGTGTCAGATAT ATACATCGATGTGCATGTATTGAACAGCGACCTTGCCGGTGCCAGTCGGATAGAATTCCGGAC

Sox6-SHL4: (Sox6 binding motif located at 25bp away from the end of nucleosomal DNA)

GCATGATTCTTAAGACCGAGTTCATCCCTTATGTGATGGACCCTATACGCGGCCGCCATCAGAAT CCCGGTGCCGAGGCCGCTCAATTGGTCGTAGACAGCTCTAGCACCGCTTAAACGCACGTACGC GCTGTCCCCCGCGTTTTAACCGCCAAGGGGATTACTCCGGACAATGGAGGCACGTGTCAGATAT ATACATCGATGTGCATGTATTGAACAGCGACCTTGCCGGTGCCAGTCGGATAGAATTCCGGAC

Sox6-SHL024: (Sox6 binding motifs located at 66bp, 46bp and 25bp away from the end of nucleosomal DNA)

GCATGATTCTTAAGACCGAGTTCATCCCTTATGTGATGGACCCTATACGCGGCCGCCATCAGAAT CCCGGTGCCGAGGCCGCTCAATTGGTCGTAGACAGCTCTAGCACCGCTTAAACGCACGTAGGA CAATGGAGGCGCGTTTTGGACAATGGAGGCATTACTCCGGACAATGGAGGCACGTGTCAGATAT ATACATCGATGTGCATGTATTGAACAGCGACCTTGCCGGTGCCAGTCGGATAGAATTCCGGAC

All Sox6 binding motif harboring 601 constructs were amplified using ${ }^{32} \mathrm{P}$ end labeled primers. The labeled DNA substrates were purified on $5 \%$ native acryl amide gel prior to use for nucleosome reconstitutions.

Nucleosome Reconstitution: Nucleosome reconstitution was performed by the salt dialysis procedure. Approximately, 500ng of 32P-labeled DNA probe containing the Sox 6 binding site and $4.5 \mu \mathrm{g}$ of chicken erythrocyte DNA (150-200 bp) as carrier were mixed with human histones- tetramers and dimers approximately in 1: $0.5: 0.5$ ratio in HFB buffer $(2 \mathrm{M} \mathrm{NaCl}, 10 \mathrm{mM}$ Tris pH7.4, $1 \mathrm{mM}$ EDTA pH 8 and $10 \mathrm{mM} \beta$-mercaptoethanol) respectively. The mixtures were transferred into dialysis tubing and the reconstitution was done by dialysis against a slowly decreasing salt buffer. The $\mathrm{NaCl}$ concentration starts at $2 \mathrm{M}$ and decreases slowly up to $500 \mathrm{mM} \mathrm{NaCl}$. Indeed, with the help of a peristaltic pump, low salt buffer is added to the high salt buffer beaker at the rate of $1.5 \mathrm{ml} / \mathrm{min}$ for 18 h. Once finished, the dialysis bags were transferred to a $300 \mathrm{mM} \mathrm{NaCl}$ buffer and left for buffer exchange for $2 \mathrm{~h}$, which was followed by a final dialysis in $10 \mathrm{mM} \mathrm{NaCl}$ buffer overnight. All $\mathrm{NaCl}$ buffers for reconstitution include $10 \mathrm{mM}$ Tris pH 7.4, $0.25 \mathrm{mM}$ EDTA, $10 \mathrm{mM} \beta$-mercaptoethanol and the desired amounts of $\mathrm{NaCl}$.

Sox6 HMG domain binding reaction: The binding reaction of Sox6 HMG domain on DNA or nucleosomes was carried out at $37^{\circ} \mathrm{C}$. Typically, Sox6 HMG domain was mixed with DNA or nucleosome $(40 \mathrm{nM})$ in a $20 \mu \mathrm{l}$ reaction containing $1 \mathrm{X}$ binding buffer (10 mM Tris, $\mathrm{pH} 7.4,75 \mathrm{mM}$ $\mathrm{NaCl}, 1 \mathrm{mM}$ EDTA, $1 \mathrm{mM}$ DTT, $100 \mathrm{mg} / \mathrm{ml} \mathrm{BSA}, 0.01 \% \mathrm{NP} 40$ and $5 \%$ glycerol). The naked DNA was supplemented with carrier nucleosomes to a final concentration equal to those of labeled nucleosomes. An aliquot of this reaction mix was used to check the formation of the Sox6 HMG 
domain:DNA or Sox6 HMG domain:nucleosome complex by 5\% native PAGE at room temperature in $0.3 \times$ Tris-borate-EDTA (TBE) buffer. The remaining aliquots were probed by UV laser footprinting.

Hydroxyl radical footprinting: Hydroxyl radical footprinting was carried out to check the strong nucleosome positioning ability of Sox 6 binding site incorporated $255 \mathrm{bp}$ of 601 constructs. The reaction was carried out in $15 \mu \mathrm{l}$ final reaction mixture in quencher free buffer placed at the bottom of an eppendorf tube. The hydroxyl radicals were generated by mixing $2.5 \mu \mathrm{l}$ each of $2 \mathrm{mM} \mathrm{FeAmSO} 4 / 4$ mM EDTA, $0.1 \mathrm{M}$ ascorbate, and $0.12 \% \mathrm{H} 2 \mathrm{O} 2$ together in a drop on the side of the reaction tube before mixing rapidly with the reaction solution. The reaction was terminated after 2 minutes by addition of $100 \mu \mathrm{L}$ stop solution ( $0.1 \%$ SDS, $25 \mathrm{mM}$ EDTA, $1 \%$ glycerol, and $100 \mathrm{mM}$ Tris, pH 7.4), and the DNA was purified by phenol/chloroform extraction and ethanol/glycogen precipitation. The DNA was resuspended in formamide loading buffer, heated for 3 minutes at $80^{\circ} \mathrm{C}$ and ran along with UV laser samples on $8 \%$ denaturing gel in $1 \mathrm{X}$ TBE buffer. The gels were dried and exposed overnight on a phosphor imager screen. The gels were scanned on phosphor imager and analyzed by MultiGauge (Fuji) software.

UV laser footprinting: The UV laser specific biphotonic lesions 8-oxoG were mapped by Fpg glycosylase which is generated in the Sox6 cognate binding sequence upon UV laser irradiation. The samples were exposed to a single high intensity UV laser pulse (Epulse $\sim 0.1 \mathrm{~J} / \mathrm{cm} 2$ ) as described in previous studies (Angelov et al., 2004; Lone et al., 2013). The DNA was then purified by phenolchloroform and ethanol/glycogen precipitated. The purified DNA was resuspended in resuspension buffer (10 mM Tris, pH 7.4, $30 \mathrm{mM} \mathrm{NaCl}, 1 \mathrm{mM}$ EDTA, $1 \mathrm{mM} \mathrm{DTT,} 100 \mu \mathrm{g} / \mathrm{ml} \mathrm{BSA}, 0.01 \% \mathrm{NP} 40$ ) and cleaved with 0.1 units of Fpg glycosylase. The DNA was lyophilized and resuspended in formamide loading buffer, heated for 3 minutes at $80^{\circ} \mathrm{C}$ and loaded on $8 \%$ sequencing gel in 1 XTBE buffer. The gels were dried and exposed overnight on a phosphor imager screen. The screens were scanned on phosphor imager and analyzed by Multi-Gauge (Fuji) software. 


\section{RESULTS}

\section{Analyzing the Sox:DNA interaction dynamics reveals the indispensable contacts for Sox recognition}

The earliest Sox:DNA complex dates back to 1995 (55). Since then, a number of Sox:DNA complexes were published, which showed that, irrespective of its type, Sox binds to the minor groove, while inducing a dramatic deformation on its cognate sequence (Figure 1A). The main residues inducing these changes were characterized as (numbered according to the Sox11 HMG sequence, pdb id: 6 778) the hydrophobic FM wedge (Phe56, Met57) and the polar Asn54 (44-46, 48, 49, 56, 57). Conventionally, it was accepted that Phe56 triggers the minor groove opening, while the $600-700$ bending is imposed by the polar interactions formed by Asn54 (Figure 1A). Next to these shapepreserving essential amino acids, the core TTGT motif is specifically recognized by Arg51, Asn54, and Tyr118. These three residues form hydrogen bonds with the Sox11 cognate TTGT, as represented in Figure $1 \mathrm{~A}$.

To trace the interaction profiles of these essential Sox amino acids, we performed two $500 \mathrm{~ns}$ long (totaling $1 \mu \mathrm{s}$ ) molecular dynamics simulations of Sox11:DNA complex (Sox11, referring to Sox11HMG with pdb id: 6t78). As a result, we observed that Arg51, Asn54, and Tyr118 interact with the DNA almost throughout the whole simulation time in a base-specific manner (Figure 1D-left,

Supplementary Table 1). We also saw that from the FM wedge, Phe56 is the one making hydrophobic interactions throughout the whole simulation time, where Met57 contacts DNA for the $50 \%$ of the simulation (Figure 1D-left, Supplementary Table 1). This analysis brought up Phe56, Arg51, Asn54, and Tyr118 as the residues indispensable to Sox11:DNA binding. For a native-like binding, these interactions should be reproduced, when Sox is bound to the NCP. We also observed that Soxbound-DNA backbone conformation differs from its initially crystallized state within the range of 0.7 2.2 A P-RMSD (Phosphorus Root Mean Square Deviation (Methods, Figure 1E - blue distribution)). For convenience, from this point forward, we will refer Sox11 as Sox.

\section{SHL2 is transparent to Sox binding}

The available nucleosomal DNA conformations, as resolved by X-Ray crystallography or cryo-EM are not wide enough to accommodate Sox binding (Supplementary Figure 1C-D). This observation led us to the plausible idea that the thermal fluctuations exerted by the nucleosomal DNA could confer a Sox-binding-competent state. We, therefore, simulated the 601-SHL2 nucleosome for $2 \mu$ s to observe whether the thermal fluctuations of the nucleosomal DNA encode enough minor groove widening to accommodate Sox encounter complex formation (Figure 1B). To construct the 601-SHL2 nucleosome, we took the 601 Widom DNA sequence, where the Sox binding motif is incorporated at the solvent-facing SHL2 (Methods). As an outcome of this, we could obtain a handful of conformations, allowing an encounter Sox:SHL2 complex formation (Figure 1E - green distribution). Among the sampled conformers, we isolated the one, fitting best to the Sox-bound-DNA conformation (pdb id: 6t78, with $1.9 \AA$ P-RMSD) (Supplementary Figure 1E-F). By using the known Sox interactions 
pattern as a template, we modeled our initial Sox:SHL2 complex (Figure 1C, Methods). This complex was then subjected to two rounds of $500 \mathrm{~ns}$ long molecular dynamics simulations, in order to allow enough time for Sox to find its native binding pose. We named the whole modeling incorporated simulation process as Dynamic Integrative Modeling (Methods). As a result of this tedious modeling cycles, we observed that Sox:SHL2 complex behaves stably during the last 300 ns of the simulations (Supplementary Figure 3A), which we took as a basis for the rest of the analyses. Tracing the PRMSD profile of Sox:SHL2 complex and comparing it to the 601-SHL2 P-RMSD profile revealed something very striking: Sox binding is indispensable to induce the extreme minor groove geometry (Figure 1E). When we concentrated on the specific interaction profiles of Sox, we observed that at the SHL2 the critical amino acids of Sox behave as in the case of Sox:DNA complex (Figure 1D). This implies that SHL2 is transparent to Sox binding, when the Sox cognate motif faces the solvent. It also tells us that the persistent Sox:DNA interaction network directed by Phe56, Arg51, Asn54, and Tyr118 is required to induce the extreme minor groove deformation.

\section{Sox can deform the DNA at SHL4, but not at the dyad}

To reveal the impact of the histone:DNA interactions on the position-dependent behavior of nucleosomal DNA, we modeled Sox binding at dyad and SHL4 (Figure 2A). During modeling, we followed the same protocol, which we used for constructing the Sox:SHL2 complex, as outlined in the previous section (Materials and Methods, Supplementary Figure 1F). We then generated two $500 \mathrm{~ns}$ long molecular dynamics simulations for each Sox:dyad and Sox:SHL4 complex. In the case of Sox:dyad, the dynamic P-RMSD profiles unveiled that Sox:dyad almost never exerts the Sox-boundDNA fingerprint conformation (Figure 2B). Also, compared to the Sox:SHL2 complex, in the case of Sox:dyad, the specific Asn54 interactions are lost, and the specific Tyr118 interactions are reduced by $50 \%$, while the hydrophobic Met57 interactions are increased by $20 \%$ (Figure $2 \mathrm{C}$ - left). Interestingly, SHL4:Sox complex reflects Sox-bound-DNA conformations during the $50 \%$ of the simulation, which lays out SHL4 as a less favorable binding site compared to SHL2. Further, at SHL4, the hydrophobic Met57:DNA interactions are further increased by $40 \%$ (Figure 2C-right panel). However, the basespecific Asn54 and Tyr118 hydrogen bonds are almost lost. These findings indicate that the more specific Sox:DNA interactions are lost, the more hydrophobic non-specific interactions prevail. They also imply that SHL4 permits solely shape reading and dyad allows no reading at all (Supplementary Figure 3B).

\section{Solvent-facing Sox binding is confirmed by the $\cdot \mathrm{OH}$ footprinting experiments}

To confirm the solvent-facing Sox binding at the dyad, SHL2, and SHL4, we used hydroxyl radical $(\cdot \mathrm{OH})$ footprinting. The $\cdot \mathrm{OH}$ footprinting is a versatile technique to analyze the binding of Sox to NCP, as $\bullet \mathrm{OH}$ radicals attack DNA via the minor groove (58-60). As Sox binds to the DNA minor groove, a footprinting should be visible at the relevant SHL site upon Sox binding. Expanding on this, we performed $\cdot \mathrm{OH}$ footprinting on a special nucleosomal DNA sequence, i.e., 601-SHL024, in isolation and when wrapped around the histones. In these experiments, we used the Sox6-HMG sequence to trace the Sox binding. In 601-SHL024, a special sequence encompassing the Sox cognate sequence 
is incorporated at dyad, SHL2, and SHL4 (Materials and Methods, Figure 3A and Supplementary Figure 4). This special DNA sequence is the same as the one we used during our in silico experiments. During our experiments, both naked DNA and nucleosomes were allowed to interact with increasing amount of Sox (the amount of Sox used for the analysis of Sox binding to the NCP was $\sim 3$-fold higher than used in the naked DNA experiments) and the samples were used for $\cdot \mathrm{OH}$ radical footprinting. As seen in Figure 3A, upon increasing the amount of Sox in the reaction mixture (where we used Sox6 here and during the rest of the experiments), a very clear protection of all three Sox recognition sequences is observed on naked DNA (Figure 3A). Protection is also observed at Sox binding sequences in histone-wrapped 601-SHL024 DNA (Figure 3A, insets). Albeit, the protection at SHL2 and SHL4 is not so well visible, since the protected sites coincide with the maximal cleavage of the DNA in the nucleosome. Of note, a very specific footprinting of Sox is detected at the nucleosome dyad, where the four middle DNA bands exhibit a strong decrease in the intensity compared to the flanking bands (see the magnified recognition sequence footprint as well as the scans at the right inset of Figure $3 \mathrm{~A}$ ). This Sox-protected $\bullet \mathrm{OH}$ cleavage pattern is very similar to the one of globular linker histone $\mathrm{H} 1$ domain in the $\mathrm{H} 1$-bound nucleosome $((2,4,61)$, see also Supplementary Figure 5A-B), which implies that the global 3D organization of Sox-dyad complex is analogous to the complex formed between the globular domain of $\mathrm{H} 1$ and the nucleosome dyad $(2,4$, $61)$.

\section{UV laser footptinting validates that the DNA shape reading is realized at SHL2 and SHL4, but not at the dyad}

To analyze the local DNA changes occurring at the minor groove of nucleosomal DNA, we performed UV laser footptinting of Sox bound 601-SHL024 DNA in free and histone-wrapped states. UV laser footprinting measures the UV laser-induced alterations in the nucleotide photoreactivity (62), which could affect the spectrum and the amount of the lesions. Since the binding of Sox to DNA alters the local structure of Sox recognition sequence, it should lead to changes in the spectrum of lesions. Such lesions are extremely sensitive to local DNA structure and can easily be mapped by alkali or enzymatic DNA strand cleavage, followed by electrophoresis under denaturing conditions at the single nucleotide resolution (63). Since a single nano- or picosecond laser pulse is used for irradiation, the generation of the lesions is achieved in an interval of time, which is shorter than the conformational transitions of the protein:DNA complex (64). So, the laser footprinting is taking a snapshot of the complex structure, while recording the Sox-induced structural signature (64). We used this method successfully in the past for mapping productive protein:DNA interactions $(17,65$, 66). Followingly, we mapped UV laser specific biphotonic 8-OxoG lesions by using Fpg glycosylase (formamidopyrimidine [fapy]-DNA glycosylase). These lesions are observed on a GG sequence, located right after the 5'-ACAA-3', complementary to Sox cognate TTGT (Supplementary Figure 6A-B and Materials and Methods). As expected, with the increase in Sox concentration, the disappearance of 8-oxoG bands is traced in the 601-SHL024 DNA constructs, indicating a deformation at the Sox cognate sequence (Figure 3B, see also Supplementary Figures 4A-B and $5 C$ ). In the case of the 601SHL024 nucleosome, the same behavior was observed at SHL2 and SHL4, while at the dyad no 
bioRxiv preprint doi: https://doi.org/10.1101/2021.12.07.471700; this version posted December 9, 2021. The copyright holder for this preprint (which was not certified by peer review) is the author/funder, who has granted bioRxiv a license to display the preprint in perpetuity. It is made available under aCC-BY-NC-ND 4.0 International license.

footprint was spotted (Figure 3B). This reveals that Sox is able to produce similar local conformational changes, i.e., minor groove widening, at SHL2 and SHL4 as in free DNA, confirming our modeling and simulation results. Identical footprinting profiles are observed when the Sox cognate sequence is incorporated at the dyad, SHL2, and SHL4 separately (Supplementary Figure 6C). 


\section{DISCUSSION}

PTFs have the remarkable ability to directly bind to chromatin for stimulating vital cellular processes. Thus, the PTF binding mechanism should be universal, where the strand-positioning of the PTF cognate sequence should not impact its accessibility on the nucleosomes. Expanding on this notion, we resolved how Sox PTF binds to its solvent-facing nucleosomal DNA sequence. Earlier, Sox binding to histone-facing cognate sequence was determined by cryo-EM (43). In the EM structure, the solvent-excluded positioning of the Sox recognition motif creates a steric clash between the two helices of Sox and the two DNA gyres (Supplementary Figure 1A). On the other hand, in our Sox:SHL2 complex, Sox tails are placed in-between the two DNA gyres, which would not impose any major structural changes (Figure 1D, Figure 2A). Strikingly, ours and Dodonova et. al.'s Sox:SHL2 complexes are of the same accuracy, compared to Sox11-bound-DNA (P-RMSD: 1.4 $\AA$ ), endorsing the validity of our initial hypothesis.

In this work, we also showed for the first time that only SHL2 acts transparent to Sox binding. This is not a surprise, as it was already demonstrated that the nucleosome displays stretching at SHL2 with a kink into the minor groove, providing a perfect recognition site for proteins (67). Relatedly, it was recently shown that SHL2 can even harbor nonspecific protein binding, as revealed by the TATAbox-binding-protein:SHL2 complex (68). At the SHL2 H3 a3- and H4 a2-helices form very few protein contacts, providing an extra flexibility to this region (69-72). All in all, it can be said that weak histoneDNA interactions at SHL2 makes SHL2 a good recognition site for Sox binding. These observations were also validated by our UV laser footprinting experiments.

Further structural analysis on our Sox:SHL complexes revealed that only at SHL2, Sox's globular a-helical HMG domain is far enough from the adjacent histones, so that the basic histones impact the Sox binding in a minimal manner (Figure 4A, Supplementary Table 2). Moreover, we observed the most stable Sox binding (with the least thermal fluctuations) at the SHL2 site, whereas the most flexible (unstable) Sox positioning is calculated for the Sox:dyad (Figure 4B). At the dyad, the histones fix the Sox binding motif in a symmetric fashion, preventing the asymmetric bending of the cognate DNA. On the other hand, the non-symmetric histone-DNA interaction profile of SHL4 permits the asymmetric deformation of the Sox-DNA. However, in this case, the N-terminal H2A Lys15 interferes with the conserved His75 of Sox, leading to a local destabilization at the tip of the Sox (Figure 4B). All these outcomes explain how SHL2 could act as a "transparent" hot spot binding site to Sox. In the light of these results, we speculate that the histone-DNA interactions are tuned at SHL2 to allow both shape and base reading of the DNA, whereas at SHL4 an non-specific shape reading is observed (Supplementary Movies 1-3).

Finally, through our experiments, we disclosed that $\cdot \mathrm{OH}$ radical footprinting of Sox at the dyad is very similar to the $\mathrm{H} 1$ globular domain bound to the dyad (Supplementary Figure $5 \mathrm{~A}-\mathrm{B}$ ). This finding suggests that different HMG proteins could be able to efficiently bind in vivo to the dyad, without requiring the presence of the recognition motif. In other words, the peculiar V-shape of the entry-exit nucleosomal DNA $(2,61)$ and the very similar shape and globular $\mathrm{H} 1$ domain-like dimensions of Sox 
bioRxiv preprint doi: https://doi.org/10.1101/2021.12.07.471700; this version posted December 9, 2021. The copyright holder for this

preprint (which was not certified by peer review) is the author/funder, who has granted bioRxiv a license to display the preprint in perpetuity. It is made available under aCC-BY-NC-ND 4.0 International license.

HMG-domain, would be sufficient for non-specific binding of HMG-domain proteins to the dyad. This could explain why the non-specific and highly abundant HMGB1/B2 chromatin proteins and the linker histone could appear to have a shared structural role in organizing linker DNA in the nucleosome (73).

All in all, our in silico and experimental observations in combination reveal that the binding of Sox is strongly nucleosomal-context-dependent, where histone-DNA interactions dictates the binding capacity of Sox, which could be valid for other PTFs as well. 


\section{DATA AVAILABILITY}

All the relevant structural models together with the relevant simulation trajectories are deposited at GitHub (https://github.com/CSB-KaracaLab/Sox-PTF). Additional data supporting the findings of this study are available from the corresponding authors upon request.

\section{SUPPLEMENTARY DATA}

Supplementary Data are available at NAR online.

\section{FUNDING}

E.K. acknowledges EMBO Installation Grant (no. 4421) and Alexander von Humboldt Foundation Return Fellowship. This work was supported by institutional funding of Izmir Biomedicine and Genome Center; Centre National de la recherche Scientifique and was benefiting from the 2232 International Fellowship for Outstanding Researchers Program of TÜBiTAK [Project No: 118C354] (the financial support received from TÜBITAK does not mean that the content of the publication is approved in a scientific sense by TÜBITAK).

Funding for open access charge: The institutional funding of Izmir Biomedicine and Genome Center

\section{ACKNOWLEDGEMENT}

All the simulations and analyses were carried out in the TUBITAK's ULAKBIM High Performance and Grid Computing Center and local HPC resources of IBG.

\section{CONFLICT OF INTEREST}

The authors declare no competing interests. 


\section{REFERENCES}

1. van Holde,K.E. (1989) Chromatin. 10.1007/978-1-4612-3490-6.

2. Bednar,J., Garcia-Saez,I., Boopathi,R., Cutter,A.R., Papai,G., Reymer,A., Syed,S.H., Lone,I.N., Tonchev,O., Crucifix,C., et al. (2017) Structure and Dynamics of a 197 bp Nucleosome in Complex with Linker Histone H1. Molecular Cell, 66, 384-397.e8.

3. Meyer,S., Becker,N.B., Syed,S.H., Goutte-Gattat,D., Shukla,M.S., Hayes,J.J., Angelov,D., Bednar,J., Dimitrov,S. and Everaers, R. (2011) From crystal and NMR structures, footprints and cryoelectron-micrographs to large and soft structures: nanoscale modeling of the nucleosomal stem. Nucleic Acids Research, 39, 9139.

4. Syed,S.H., Goutte-Gattat,D., Becker,N., Meyer,S., Shukla,M.S., Hayes,J.J., Everaers,R., Angelov,D., Bednar,J. and Dimitrov,S. (2010) Single-base resolution mapping of H1-nucleosome interactions and 3D organization of the nucleosome. Proceedings of the National Academy of Sciences of the United States of America, 107, 9620-9625.

5. Thoma,F., Koller,T. and Klug,A. (1979) Involvement of histone H1 in the organization of the nucleosome and of the salt-dependent superstructures of chromatin. The Journal of Cell Biology, 83, 403.

6. van Holde,K.E. (1989) Chromatin. 10.1007/978-1-4612-3490-6.

7. Kobayashi,W. and Kurumizaka,H. (2019) Structural transition of the nucleosome during chromatin remodeling and transcription. Current Opinion in Structural Biology, 59, 107-114.

8. Zhou,C.Y., Johnson,S.L., Gamarra,N.I. and Narlikar,G.J. (2016) Mechanisms of ATP-Dependent Chromatin Remodeling Motors. Annual review of biophysics, 45, 153-181.

9. Clapier,C.R., Iwasa,J., Cairns,B.R. and Peterson,C.L. (2017) Mechanisms of action and regulation of ATP-dependent chromatin-remodelling complexes. Nature reviews. Molecular cell biology, 18, 407.

10. Narlikar,G.J., Sundaramoorthy,R. and Owen-Hughes,T. (2013) Mechanisms and Functions of ATPDependent Chromatin-Remodeling Enzymes. Cell, 154, 490.

11. Wolffe,A.P., Almouzni,G., Ura,K., Pruss,D. and Hayes,J.J. (1993) Transcription Factor Access to DNA in the Nucleosome. Cold Spring Harbor Symposia on Quantitative Biology, 58, 225-235.

12. Beato,M. and Eisfeld,K. (1997) Transcription factor access to chromatin Oxford University Press.

13. Eisfeld,K., Candau,R., Truss,M. and Beato,M. (1997) Binding of NF1 to the MMTV promoter in nucleosomes: influence of rotational phasing, translational positioning and histone $\mathrm{H} 1 \mathrm{Oxford}$ University Press.

14. Vitolo,J.M., Yang,Z., Basavappa,R. and Hayes,J.J. (2004) Structural Features of Transcription Factor IIIA Bound to a Nucleosome in Solution. Molecular and Cellular Biology, 24, 697-707. 
15. Vitolo,J.M., Thiriet,C. and Hayes,J.J., (2000) MCB.20.6.2167-2175.2000. Molecular and Cellular Biology, 20, 20167-20175.

16. le Dily,F.L., Baù,D., Pohl,A., Vicent,G.P., Serra,F., Soronellas,D., Castellano,G., Wright,R.H.G., Ballare,C., Filion,G., et al. (2014) Distinct structural transitions of chromatin topological domains correlate with coordinated hormone-induced gene regulation. Genes and Development, 28, 2151-2162.

17. Lone,I.N., Shukla,M.S., Charles Richard,J.L., Peshev,Z.Y., Dimitrov,S. and Angelov,D. (2013) Binding of NF-KB to nucleosomes: effect of translational positioning, nucleosome remodeling and linker histone H1. PLoS genetics, 9.

18. Hsu,H.T., Chen,H.M., Yang,Z., Wang,J., Lee,N.K., Burger,A., Zaret,K., Liu,T., Levine,E. and Mango,S.E. (2015) Recruitment of RNA polymerase II by the pioneer transcription factor PHA-4. Science, 348, 1372.

19. Iwafuchi-Doi,M., Donahue,G., Kakumanu,A., Watts,J.A., Mahony,S., Pugh,B.F., Lee,D., Kaestner,K.H. and Zaret,K.S. (2016) The Pioneer Transcription Factor FoxA Maintains an Accessible Nucleosome Configuration at Enhancers for Tissue-Specific Gene Activation. Molecular cell, 62, 79-91.

20. Soufi,A., Garcia,M.F., Jaroszewicz,A., Osman,N., Pellegrini,M. and Zaret,K.S. (2015) Pioneer Transcription Factors Target Partial DNA Motifs on Nucleosomes to Initiate Reprogramming. Cell, 161, 555.

21. Zaret,K.S., Lerner,J. and Iwafuchi-Doi,M. (2016) Chromatin Scanning by Dynamic Binding of Pioneer Factors. Molecular cell, 62, 665-667.

22. Grossman,S.R., Engreitz,J., Ray,J.P., Nguyen,T.H., Hacohen,N. and Lander,E.S. (2018) Positional specificity of different transcription factor classes within enhancers. Proceedings of the National Academy of Sciences of the United States of America, 115, E7222-E7230.

23. Baxevanis,A.D., Bryant,S.H. and Landsman,D. (1995) Homology model building of the HMG-1 box structural domain. Nucleic Acids Research, 23, 1019-1029.

24. Jones,D.N., Searles,M.A., Shaw,G.L., Churchill,M.E., Ner,S.S., Keeler,J., Travers,A.A. and Neuhaus,D. (1994) The solution structure and dynamics of the DNA-binding domain of HMG-D from Drosophila melanogaster. Structure (London, England : 1993), 2, 609-627.

25. Landsman,D. and Bustin,M. (1993) A signature for the HMG-1 box DNA-binding proteins. BioEssays : news and reviews in molecular, cellular and developmental biology, 15, 539-546.

26. Read,C.M., Cary,P.D., Crane-robinson,C., Driscoll,P.C. and Norman,D.G. (1993) Solution structure of a DNA-binding domain from HMG1. Nucleic Acids Research, 21, 3427.

27. Agresti,A., Lupo,R., Bianchi,M.E. and Müller,S. (2003) HMGB1 interacts differentially with members of the Rel family of transcription factors. Biochemical and Biophysical Research Communications, 302, 421-426. 
28. Balliano,A., Hao,F., Njeri,C., Balakrishnan,L. and Hayes,J.J. (2017) HMGB1 stimulates activity of polymerase $\beta$ on nucleosome substrates. Biochemistry, 56, 647-656.

29. Bianchi,M.E. and Agresti,A. (2005) HMG proteins: dynamic players in gene regulation and differentiation. Current Opinion in Genetics \& Development, 15, 496-506.

30. Degryse,B., Bonaldi,T., Scaffidi,P., Müller,S., Resnati,M., Sanvito,F., Arrigoni,G. and Bianchi,M.E. (2001) The high mobility group (HMG) boxes of the nuclear protein HMG1 induce chemotaxis and cytoskeleton reorganization in rat smooth muscle cells. The Journal of cell biology, 152, 1197-1206.

31. Palozola,K.C., Lerner,J. and Zaret,K.S. (2018) A changing paradigm of transcriptional memory propagation through mitosis. Nature Reviews Molecular Cell Biology 2018 20:1, 20, 55-64.

32. Štros,M., Launholt,D. and Grasser,K.D. (2007) The HMG-box: a versatile protein domain occurring in a wide variety of DNA-binding proteins. Cellular and Molecular Life Sciences 2007 64:19, 64, 2590-2606.

33. Sutrias-Grau,M., Bianchi,M.E. and Bernués,J. (1999) High Mobility Group Protein 1 Interacts Specifically with the Core Domain of Human TATA Box-binding Protein and Interferes with Transcription Factor IIB within the Pre-initiation Complex *. Journal of Biological Chemistry, 274, 1628-1634.

34. Thomas,J.O. and Travers,A.A. (2001) HMG1 and 2, and related 'architectural' DNA-binding proteins. Trends in Biochemical Sciences, 26, 167-174.

35. Frum,T., Murphy,T.M. and Ralston,A. (2018) HIPPO signaling resolves embryonic cell fate conflicts during establishment of pluripotency in vivo. elife, $\mathbf{7 .}$

36. Julian,L.M., McDonald,A.C. and Stanford,W.L. (2017) Direct reprogramming with SOX factors: masters of cell fate. Current opinion in genetics \& development, 46, 24-36.

37. Lourenço,A.R. and Coffer,P.J. (2017) SOX4: Joining the Master Regulators of Epithelial-toMesenchymal Transition? Trends in Cancer, 3, 571-582.

38. Tiwari,N., Tiwari,V.K., Waldmeier,L., Balwierz,P.J., Arnold,P., Pachkov,M., Meyer-Schaller,N., Schübeler,D., vanNimwegen,E. and Christofori,G. (2013) Sox4 Is a Master Regulator of Epithelial-Mesenchymal Transition by Controlling Ezh2 Expression and Epigenetic Reprogramming. Cancer Cell, 23, 768-783.

39. Malarkey,C.S. and Churchill,M.E.A. (2012) The high mobility group box: the ultimate utility player of a cell. Trends in Biochemical Sciences, 37, 553-562.

40. Hou,L., Srivastava,Y. and Jauch,R. (2017) Molecular basis for the genome engagement by Sox proteins. Seminars in cell \& developmental biology, 63, 2-12.

41. Klaus,M., Prokoph,N., Girbig,M., Wang,X., Huang,Y.H., Srivastava,Y., Hou,L., Narasimhan,K., Kolatkar,P.R., Francois,M., et al. (2016) Structure and decoy-mediated inhibition of the SOX18/Prox1-DNA interaction. Nucleic Acids Research, 44, 3922. 
42. Rohs, R., Jin,X., West,S.M., Joshi,R., Honig,B. and Mann,R.S. (2010) Origins of specificity in protein-DNA recognition. Annual Review of Biochemistry, 79, 233-269.

43. Dodonova,S.O., Zhu,F., Dienemann,C., Taipale,J. and Cramer,P. (2020) Nucleosome-bound SOX2 and SOX11 structures elucidate pioneer factor function. Nature 2020 580:7805, 580, 669-672.

44. Cerdan,R., Payet,D., Yang,J.-C., Travers,A.A. and Neuhaus,D. (2001) HMG-D complexed to a bulge DNA: An NMR model. Protein Science : A Publication of the Protein Society, 10, 504.

45. Churchill,M.E.A., Jones,D.N.M., Glaser,T., Hefner,H., Searles,M.A. and Travers,A.A. (1995) HMG-D is an architecture-specific protein that preferentially binds to DNA containing the dinucleotide TG. The EMBO Journal, 14, 1264.

46. Dragan,A.I., Klass,J., Read,C., Churchill,M.E.A., Crane-Robinson,C. and Privalov,P.L. (2003) DNA Binding of a Non-sequence-specific HMG-D Protein is Entropy Driven with a Substantial Nonelectrostatic Contribution. Journal of Molecular Biology, 331, 795-813.

47. Dragan,A.I., Read,C.M., Makeyeva,E.N., Milgotina,E.I., Churchill,M.E.A., Crane-Robinson,C. and Privalov,P.L. (2004) DNA binding and bending by HMG boxes: energetic determinants of specificity. Journal of molecular biology, 343, 371-393.

48. Lnenicek-Allen,M., Read,C.M. and Crane-Robinson,C. (1996) The DNA bend angle and binding affinity of an HMG box increased by the presence of short terminal arms. Nucleic Acids Research, 24, 1047.

49. Read,C.M., Cary,P.D., Preston,N.S., Lnenicek-Allen,M. and Crane-Robinson1,C. (1994) The DNA sequence specificity of HMG boxes lies in the minor wing of the structure. The EMBO Journal, 13, 5639-5646.

50. Vasudevan,D., Chua,E.Y.D. and Davey,C.A. (2010) Crystal Structures of Nucleosome Core Particles Containing the "601" Strong Positioning Sequence. Journal of Molecular Biology, 403, 1-10.

51. van der Spoel,D., Lindahl,E., Hess,B., Groenhof,G., Mark,A.E. and Berendsen,H.J.C. (2005) GROMACS: fast, flexible, and free. Journal of computational chemistry, 26, 1701-1718.

52. Ivani,I., Dans,P.D., Noy,A., Pérez,A., Faustino,I., Hospital,A., Walther,J., Andrio,P., Goñi,R., Balaceanu,A., et al. (2016) Parmbsc1: a refined force field for DNA simulations. Nature methods, 13, 55-58.

53. Lu,X.J. and Olson,W.K. (2008) 3DNA: a versatile, integrated software system for the analysis, rebuilding and visualization of three-dimensional nucleic-acid structures. Nature Protocols 2008 3:7, 3, 1213-1227.

54. Karaca,E., Rodrigues,J.P.G.L.M., Graziadei,A., Bonvin,A.M.J.J. and Carlomagno,T. (2017) M3: an integrative framework for structure determination of molecular machines. Nature methods, 14, 897-902. 
55. Werner,M.H., Huth,J.R., Gronenborn,A.M. and Clore,G.M. (1995) Molecular Basis of Human 46X,Y Sex Reversal Revealed from the Three-Dimensional Solution Structure of the Human SRYDNA Complex.

56. Dragan,A.I., Read,C.M., Makeyeva,E.N., Milgotina,E.I., Churchill,M.E.A., Crane-Robinson,C. and Privalov,P.L. (2004) DNA binding and bending by HMG boxes: energetic determinants of specificity. Journal of molecular biology, 343, 371-393.

57. Etheve,L., Martin,J. and Lavery,R. (2016) Dynamics and recognition within a protein-DNA complex: A molecular dynamics study of the SKN-1/DNA interaction. Nucleic Acids Research, 44, 1440-1448.

58. Dixon,W.J., Hayes,J.J., Levin,J.R., Weidner,M.F., Dombroski,B.A. and Tullius,T.D. (1991) Hydroxyl radical footprinting. Methods in Enzymology, 208, 380-413.

59. Jagannathan,I. and Hayes,J.J. (2009) Hydroxyl radical footprinting of protein-DNA complexes. Methods in molecular biology (Clifton, N.J.), 543, 57-71.

60. Churchill,M.E.A., Hayes,J.J. and Tullius,T.D. (1990) Detection of Drug Binding to DNA by Hydroxyl Radical Footprinting. Relationship of Distamycin Binding Sites to DNA Structure and Positioned Nucleosomes on 5s RNA Genes of Xenopus+.

61. Garcia-Saez,I., Menoni,H., Boopathi,R., Shukla,M.S., Soueidan,L., Noirclerc-Savoye,M., le Roy,A., Skoufias,D.A., Bednar,J., Hamiche,A., et al. (2018) Structure of an H1-Bound 6-Nucleosome Array Reveals an Untwisted Two-Start Chromatin Fiber Conformation. Molecular cell, 72, 902915.e7.

62. Douki,T., Angelov,D. and Cadet,J. (2001) UV Laser Photolysis of DNA: Effect of Duplex Stability on Charge-Transfer Efficiency. Journal of the American Chemical Society, 123, 11360-11366.

63. Angelov,D., Khochbin,S. and Dimitrov,S. (1999) UV Laser Footprinting and Protein-DNA Crosslinking. Methods in molecular biology (Clifton, N.J.), 119, 481-495.

64. Pashev,I.G., Dimitrov,S.I. and Angelov,D. (1991) Crosslinking proteins to nucleic acids by ultraviolet laser irradiation. Trends in biochemical sciences, 16, 323-326.

65. Angelov,D., Lenouvel,F., Hans,F., Muller,C.W., Bouvet,P., Bednar,J., Moudrianakis,E.N., Cadet,J.-L. and Dimitrov,S. (2004) The histone octamer is invisible when NF-KAPPAB binds to the nucleosome. Biochemistry and Molecular Biology, 10.1074/jbc.M407235200.

66. Angelov,D., Novakov,E., Khochbin,S. and Dimitrov,S. (1999) Ultraviolet Laser Footprinting of Histone $\mathrm{H} 1^{\circ}$-Four-Way Junction DNA Complexes + . Biochemistry, 38, 11333-11339.

67. Tan,S. and Davey,C.A. (2011) Nucleosome structural studies. Current Opinion in Structural Biology, 21, 128-136.

68. Wang,L., Wang,E., Prado Balcazar,J., Wu,Z., Xiang,K., Wang,Y., Huang,Q., Negrete,M., Chen,K.Y., Li,W., et al. (2021) Chromatin Remodeling of Colorectal Cancer Liver Metastasis is Mediated by an HGF-PU.1-DPP4 Axis. Advanced Science, 8. 
bioRxiv preprint doi: https://doi.org/10.1101/2021.12.07.471700; this version posted December $9,2021$. The copyright holder for this

preprint (which was not certified by peer review) is the author/funder, who has granted bioRxiv a license to display the preprint in perpetuity. It is made available under aCC-BY-NC-ND 4.0 International license.

69. Clapier,C.R. (2021) Sophisticated conversations between chromatin and chromatin remodelers, and dissonances in cancer. International Journal of Molecular Sciences, 22.

70. Zhu,F., Farnung,L., Kaasinen,E., Sahu,B., Yin,Y., Wei,B., Dodonova,S.O., Nitta, K.R., Morgunova,E., Taipale,M., et al. (2018) The interaction landscape between transcription factors and the nucleosome. Nature, 562, 76-81.

71. Chua,E.Y.D., Vasudevan,D., Davey,G.E., Wu,B. and Davey,C.A. (2012) The mechanics behind DNA sequence-dependent properties of the nucleosome. Nucleic Acids Research, 40, 6338-6352.

72. Lobbia,V.R., Trueba Sanchez,M.C. and van Ingen,H. (2021) Beyond the Nucleosome:

Nucleosome-Protein Interactions and Higher Order Chromatin Structure. Journal of Molecular Biology, 433.

73. Ura,K., Nightingale,K. and Wolffe,A.P. (1996) Differential association of HMG1 and linker histones $\mathrm{B} 4$ and $\mathrm{H} 1$ with dinucleosomal DNA: structural transitions and transcriptional repression. The EMBO Journal, 15, 4959. 


\section{FIGURES}
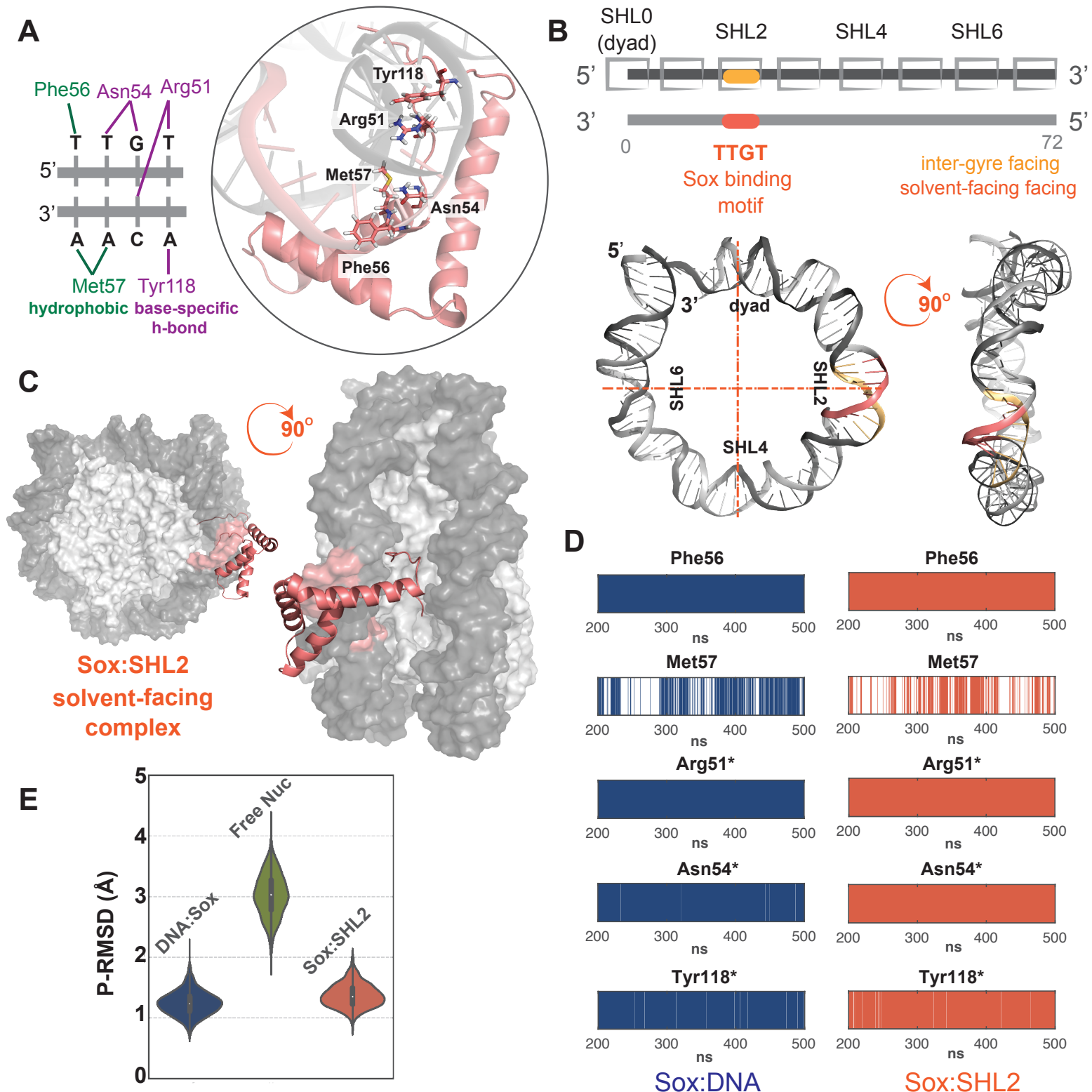

D
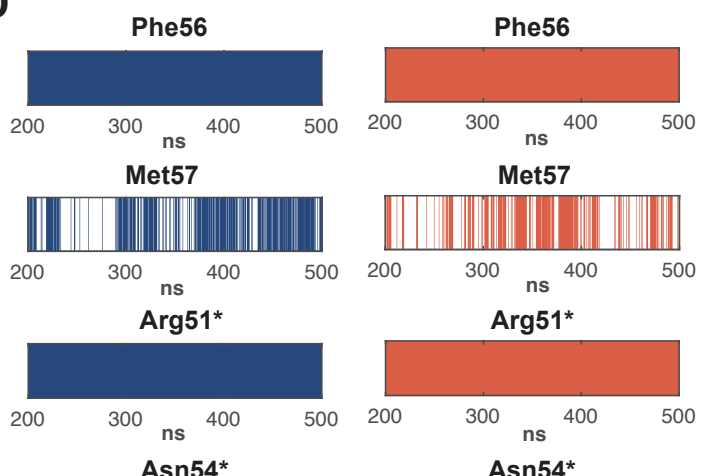

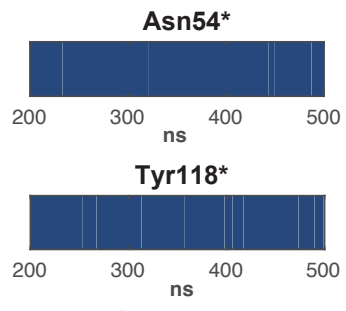

Sox:DNA

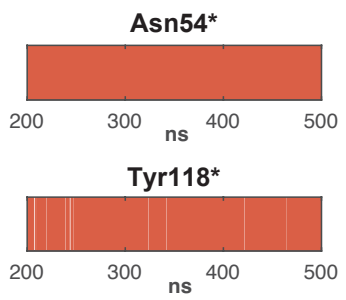

Sox:SHL2

Figure 1. (A) The essential Sox:DNA interactions. The Sox:DNA interactions essential to Sox:DNA recognition are demonstrated in sticks on Sox11:DNA complex (pdb id: 6t78). The core TTGT and its complementary Sox binding motif is specifically recognized by the hydrogen bonds formed by Arg51, Asn54, and Tyr118, and hydrophobic interactions by Phe56 and Met57. Hydrophobic interaction and base-specific hydrogen bond labels are shown in green and purple, respectively. (B) The Sox cognate sequence can be placed either on the solvent-facing or inter-gyre facing strand. The representative coordinates of each unique super helical location (SHL) is highlighted with a box. The corresponding solvent-facing (salmon) or inter-gyre-facing (orange) Sox cognate sequence (TTGT) positioning at the SHL2 are mapped on the nucleosomal DNA. (C) The solvent facing Sox:SHL2 complex model. The model is shown from front and side views, where histones and nucleosomal DNA are shown as surface and colored with light and dark gray, respectively, and Sox is shown as cartoon and colored with salmon. (D) The Sox:DNA (dark blue) and Sox:SHL2 (salmon) interaction profiles of the essential 
bioRxiv preprint doi: https://doi.org/10.1101/2021.12.07.471700; this version posted December 9, 2021. The copyright holder for this

preprint (which was not certified by peer review) is the author/funder, who has granted bioRxiv a license to display the preprint in perpetuity. It is made available under aCC-BY-NC-ND 4.0 International license.

Sox amino acids. Each barcode plot shows the presence of the denoted amino acid interaction with the DNA (within the equilibrated simulation time frame). The prevalent base-specific interactions formed by the Arg51, Asn54, and Tyr118 are presented for Sox:DNA and Sox:SHL2, respectively and highlighted with asterisk. (E) The MD-driven phosphate root mean square deviations (P-RMSDs) to the native Sox-bound-DNA conformation ( $p d b$ id 6t78). The P-RMSD distributions of the Sox cognate sequence, derived from Sox:DNA (dark blue), free nucleosomal SHL2 DNA (green), and Sox-bound SHL2 nucleosomal DNA (salmon) simulations. The persistence rate of each interaction is given in Supplementary Table 1. 
A Sox:dyad solvent-facing complex

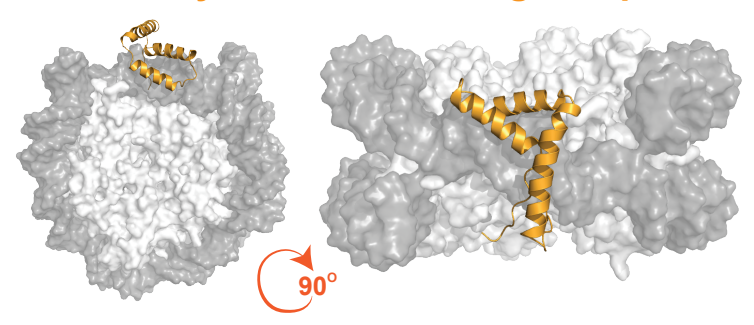

Sox:SHL4 solvent-facing complex

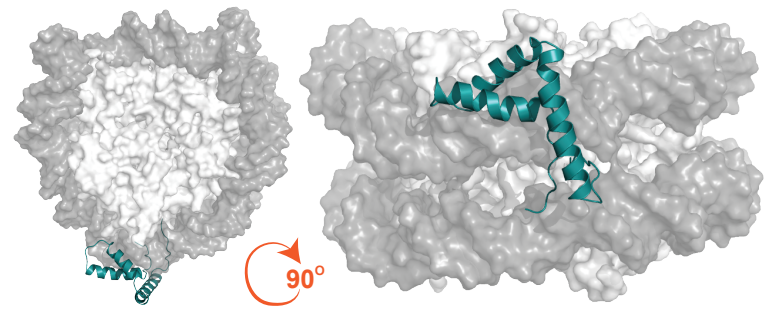

C

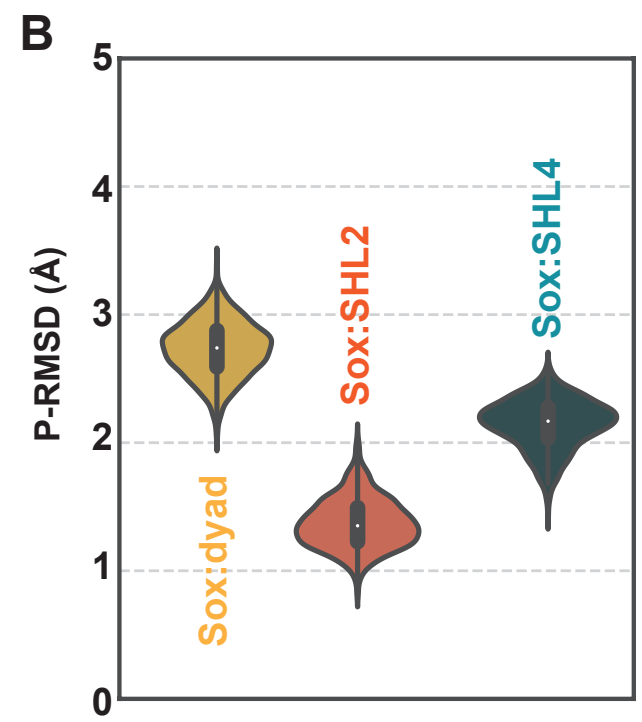

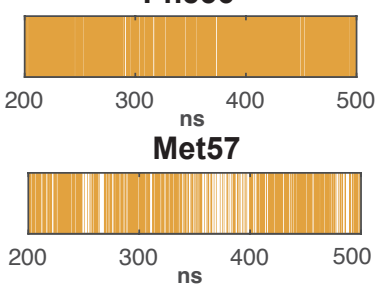

Arg51*

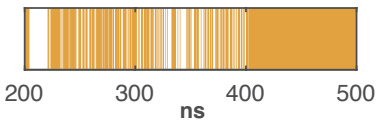

Asn54*

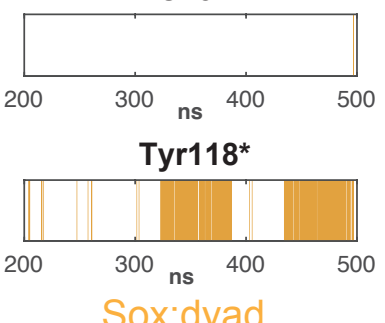

Phe56

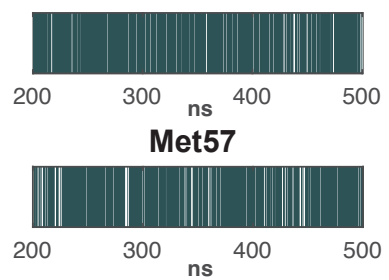

Arg51*

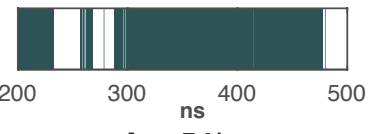

Asn54*

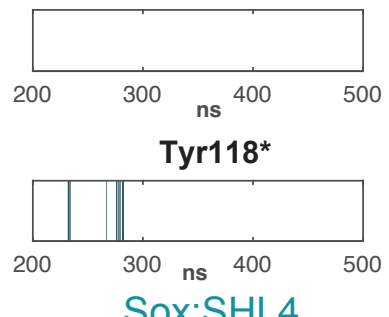

Figure 2. (A) The solvent facing Sox:dyad (orange) and Sox:SHL4 (green) complex models. The models are shown from front and side views, where histones and nucleosomal DNA are represented in surface and colored in light and dark gray, respectively. Sox is presented in orange and green cartoon for Sox:dyad and Sox:SHL4 binding, respectively. (B) The MD-driven P-RMSDs of each Sox:SHL complex to the Sox-bound-DNA conformation. P-RMSD distributions of the Sox cognate sequence, derived from Sox:dyad (orange ), Sox:SHL2 (salmon), Sox:SHL4 (dark green). (C) The Sox:DNA interaction profiles of the essential Sox amino acids at the dyad and SHL4. Each barcode plot shows the presence of the denoted amino acid interaction with the DNA (within the equilibrated simulation time frame). The prevalent the base-specific interactions formed by the Arg51, Asn54, and Tyr118 are highlighted with asterik. The persistence rate of each interaction is given in Supplementary Table 1. 
A

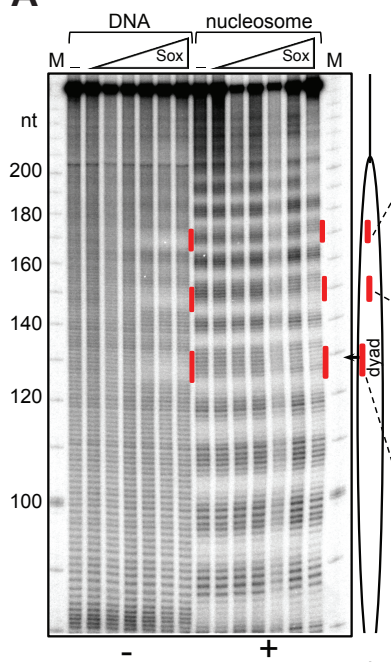

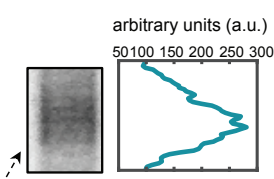

$\square$
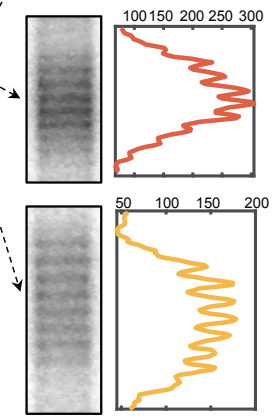

-
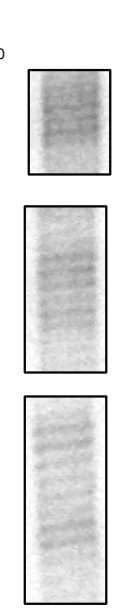

$+$
B

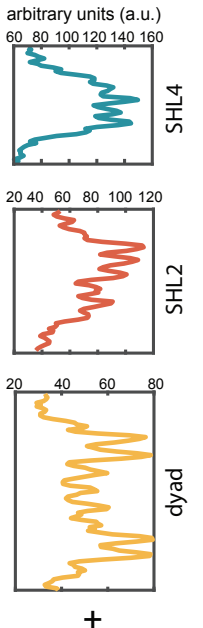

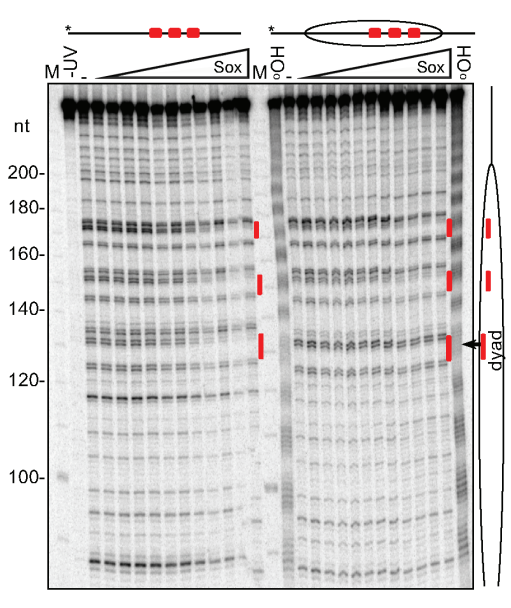

Figure 3. (A) Three Sox recognition sites are accessible to Sox binding within the nucleosome. $\cdot \mathrm{OH}$ radical footprinting patterns of Sox-DNA and Sox-nucleosome complexes, bearing the three recognition sites of Sox. After $\cdot \mathrm{OH}$ treatment of the complexes, the cleaved DNA fragments were purified and separated on $8 \%$ sequencing gel and visualized by autoradiography (left). Right, higher magnification of the indicated Sox binding sites. $\cdot \mathrm{OH}$ cleavage patterns of in un-bound (-) and Soxbound particle $(+)$, containing the three Sox recognitions sites are shown. Vertical red lines correspond to Sox binding sites; oval to the schematics of the nucleosome, where the dyad is indicated with an arrow. (B) UV laser footprinting patterns of the Sox-DNA and Sox-nucleosome complexes bearing a Sox recognition sequence at 601-SHL024. The complex was irradiated with a single 5 nanoseconds UV laser $266 \mathrm{~nm}$ pulse (Epulse, $0.1 \mathrm{~J} / \mathrm{cm} 2$ ) and DNA was purified from the samples. After treatment of the purified DNA with Fpg glycosylase, the cleaved DNA fragments were separated on $8 \%$ sequencing gel and visualized by autoradiography. Red vertical lines and red squares mark the Sox binding sites, M marks the molecular mass, oval represent the schematics of the nucleosome, and the dyad is indicated with an arrow. -UV refers to the control, non-UV irradiated and Fpg treated sample. 

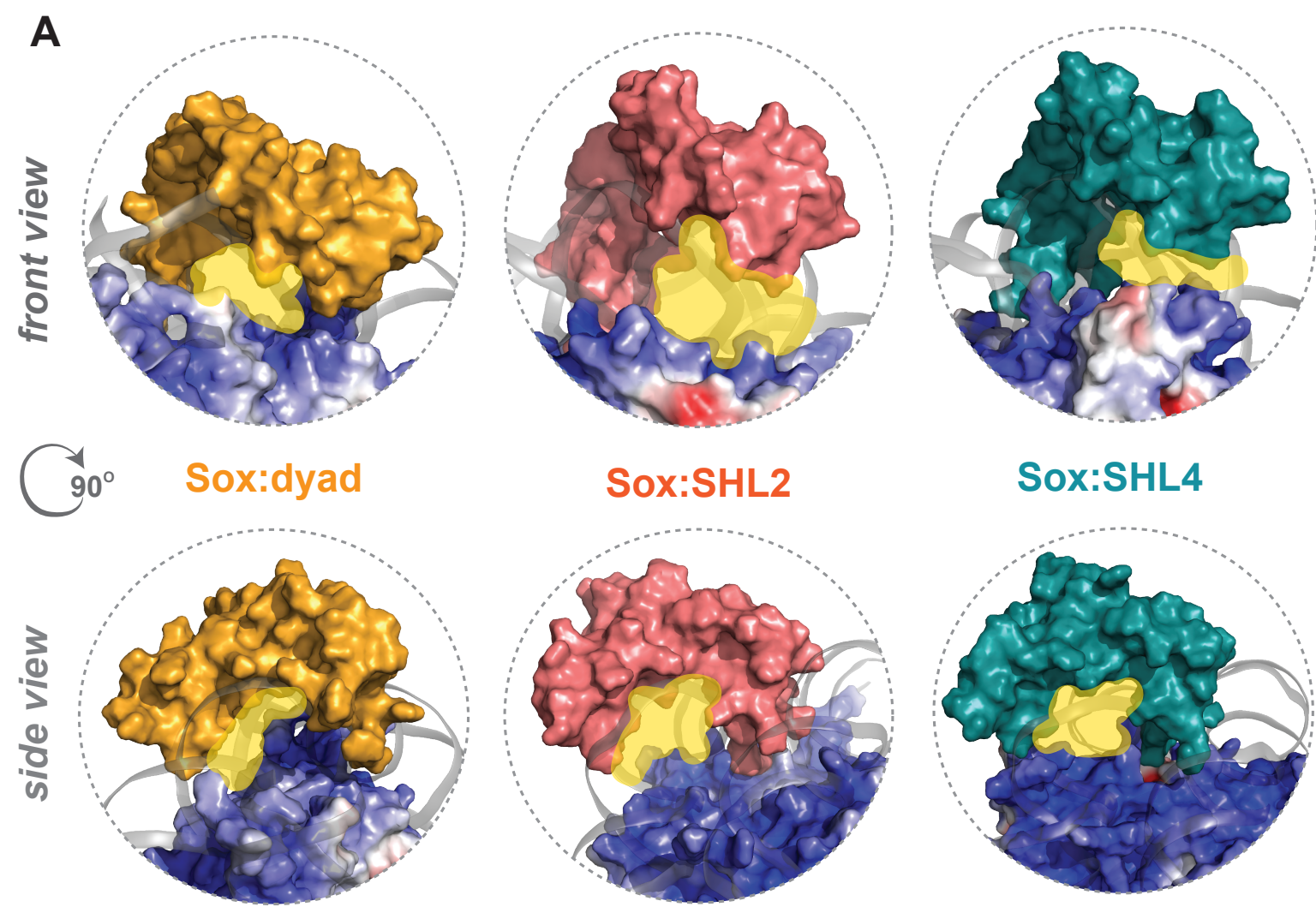

SOX:SHL2

\section{Sox:SHL4}
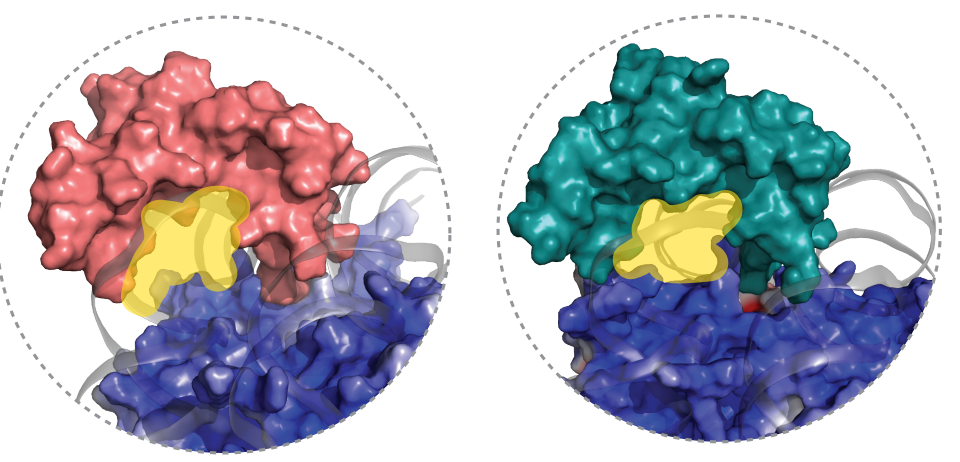

B

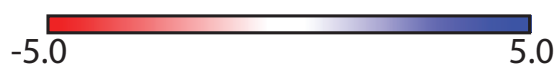

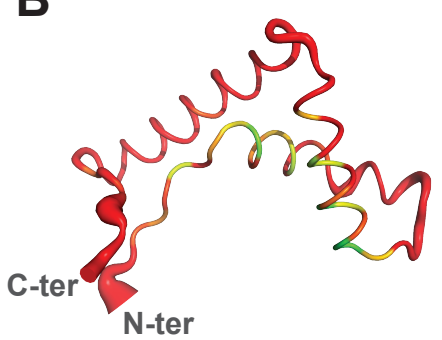

Sox at dyad

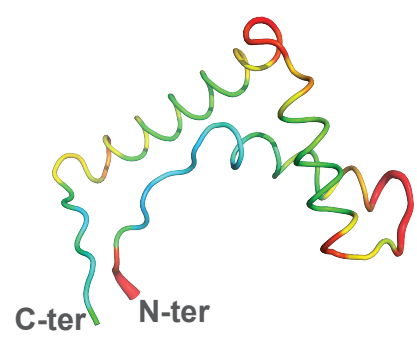

Sox at SHL2

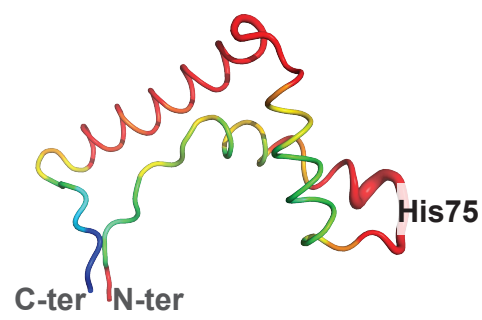

Sox at SHL4

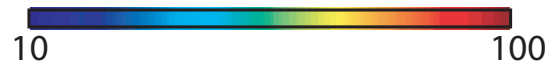

Figure 4. (A) SHL2 is transparent to Sox binding. The side of the Sox-HMG boomerang is far enough for not to feel the basic histone context only at the SHL2 binding site. The nucleosomal DNAs are demonstrated as cartoon and colored in dark gray. Histones are shown as surface and colored according to their electrostatic potentials, where red represents negatively charged $(-5)$ regions and blue represents positively charged $(+5)$ ones. (B) Sox binds the most stable at SHL2. The Sox PTFs deduced from the MD simulations of Sox:dyad (left), Sox:SHL2 (middle) and Sox:SHL4 (rigth) are colored according to their temperature factors. Blue and red colors depict the most rigid and the most flexible regions, respectively. The cartoon thickness linearly scales with the amount of thermal fluctuations. When Sox is bound to the SHL2, it has the most stable conformation. 